UCRL-ID-129493

\title{
FXR Accelerator Cavity Impedance Experiments
}

\author{
Carlos A. Avalle
}

January 5, 1998

This is an informal report intended primarily for internal or limited external distribution. The opinions and conclusions stated are those of the author and may or may not be those of the Laboratory.

Work performed under the auspices of the U.S. Department of Energy by the Lawrence Livermore National Laboratory under Contract W-7405-Eng-48. 


\section{DISCLAIMER}

This document was prepared as an account of work sponsored by an agency of the United States Government. Neither the United States Government nor the University of California nor any of their employees, makes any warranty, express or implied, or assumes any legal liability or responsibility for the accuracy, completeness, or usefulness of any information, apparatus, product, or process disclosed, or represents that its use would not infringe privately owned rights. Reference herein to any specific commercial product, process, or service by trade name, trademark, manufacturer, or otherwise, does not necessarily constitute or imply its endorsement, recommendation, or favoring by the United States Government or the University of California. The views and opinions of authors expressed herein do not necessarily state or reflect those of the United States Government or the University of California, and shall not be used for advertising or product endorsement purposes.

This report has been reproduced directly from the best available copy.

Available to DOE and DOE contractors from the Office of Scientific and Technical Information P.O. Box 62, Oak Ridge, TN 37831

Prices available from (615) 576-8401, FTS 626-8401

Available to the public from the National Technical Information Service

U.S. Department of Commerce 5285 Port Royal Rd. Springfield, VA 22161 


\title{
FXR Accelerator Cavity Impedance Experiments
}

\author{
Carlos A. Avalle
}

One of the goals of the present Flash X-Ray (FXR) accelerator upgrade effort [1][2] at Lawrence Livermore National Laboratory (LLNL) is to reduce the cavity transverse impedance, since it has been shown that beam stability is significantly affected by this parameter [3]. Recently, we have evaluated various techniques and cell modifications to accomplish that, both through lab measurements and computer models. A spare cell, identical in every way to cells in the accelerator, was specially modified for the experiments. The impedance measurements were done without the beam, by applying twin-wire techniques. This report describes the results of these experiments and suggests possible cell modifications to improve their performance. The techniques and modifications which are suggested might also be applicable to AHF and DARHT-2 long-pulse accelerator development.

\section{Experimental Setup}

A number of modifications were tested on a FXR cell to evaluate the effect on transverse impedance. Figure 1 shows a cross-section of the cell with the modifications. A large ferrite toroid was embedded in the end plate that forms a part of the accelerating gap. This modification was mainly targeted at end cells in each accelerator section, as these could be most readily modified in this manner. A different approach would be required for inner cells which would not be as accessible. For these cells, we tested flexible RF absorbers which covered the walls of the vacuum housing. These absorber sheets could be inserted into the cavity through a vacuum port without major disassembly.

The instrumentation and experimental hardware used for the RF measurements are shown in Figure 2. A section of the accelerator was removed from

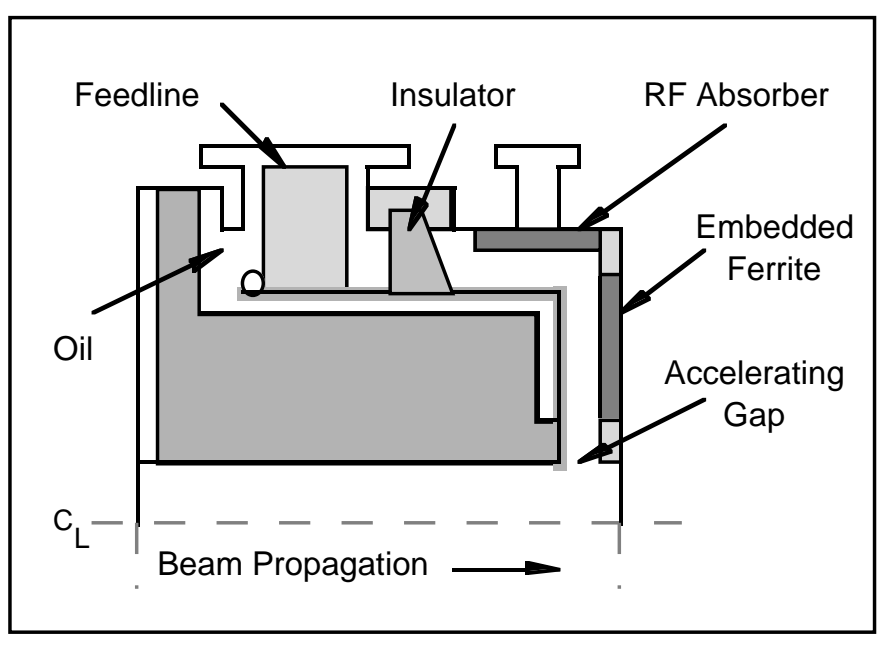

Figure 1. Cross-section of the cell with the modifications
FXR as part of maintenance and upgrade activities and the opportunity was taken to perform these measurements.

Figure 3 illustrates the measurement setup. A twin-wire transmission line is inserted into the beam pipe and supported by Styrofoam holders. The transmission line is connected to a Network Analyzer (NA) through a balun which performs two functions: 1) it provides the correct impedance match between the NA and the transmission line, 2) it provides the correct phase relationship between the wires to excite transverse modes. Matching sections were added to the end plates of the cell. These matching

sections were machined to specific tolerances whereby impedances are well defined. By utilizing matching sections of different lengths it is possible to create a standard set of calibration fixtures (Thru-Reflection-Line). After the NA is calibrated, matching sections are 


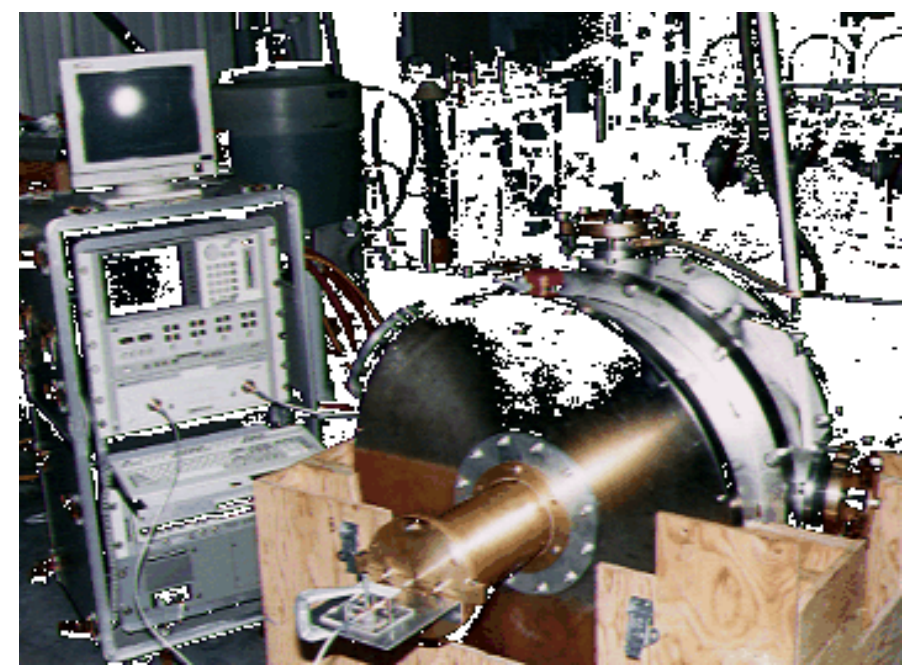

added to the test cell and a complete 2port, S-parameter measurement is performed over some frequency range. The complex data is then corrected to subtract NA, cable, and matching section effects, and normalized by the transmission line impedance. This measurement technique was originally developed by Walling [4], and later refined at Lawrence Livermore National Laboratory for FXR application.

Figure 2. Instrumentation and experimental hardware

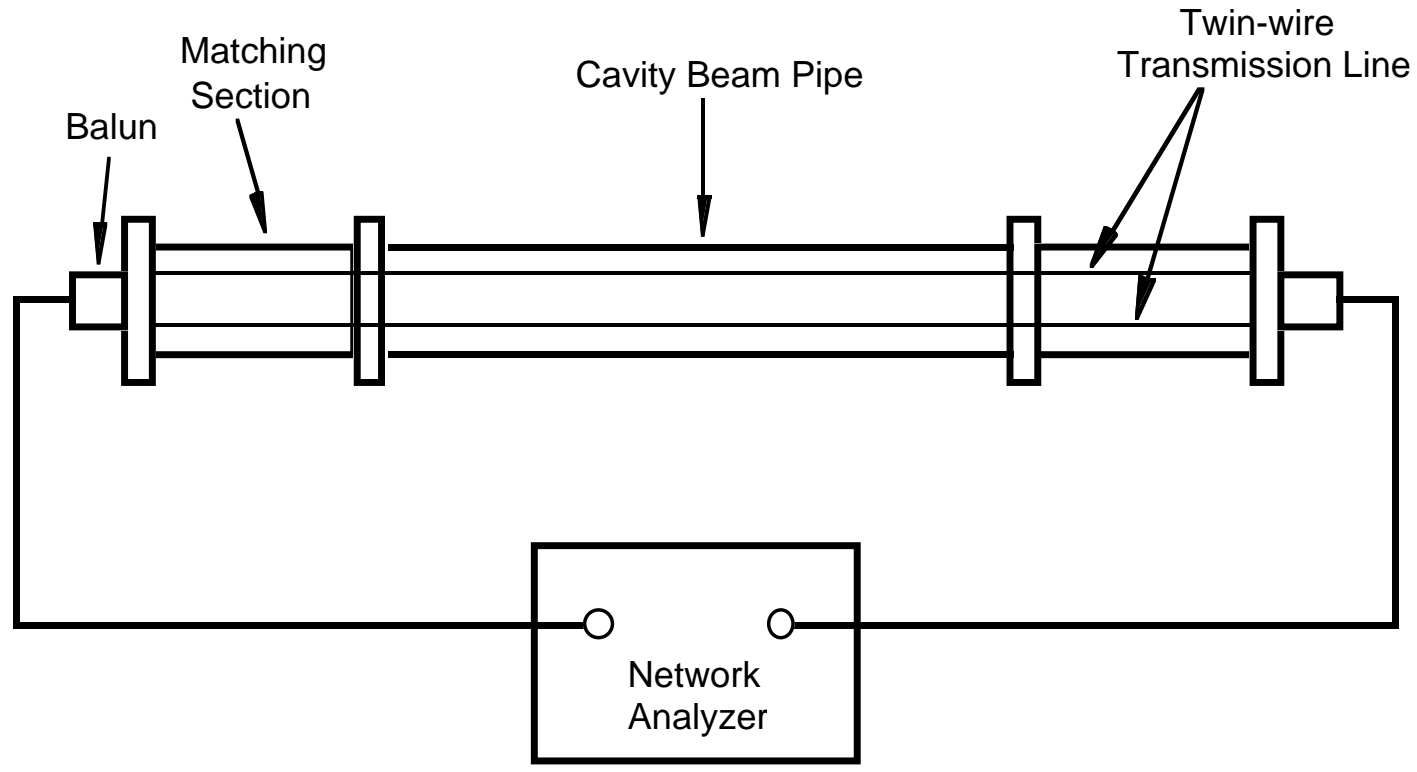

Figure 3. Measurement setup

\section{Corner Reflector Tests}

The $\mathrm{TM}_{1 \mathrm{n}}$ modes are beam deflecting modes of cavities, and the transverse coupling impedance is a measure of how efficiently the beam interacts with these modes. For these experiments, the $\mathrm{TM}_{11}$ dipole mode was excited in the beam pipe test section by driving a pair of parallel conductors out of phase. The measurements were done over a fairly wide frequency range, from $0.175 \mathrm{MHz}$ to $1.4 \mathrm{GHz}$, however, results are only shown to $1.1 \mathrm{GHz}$, since above that frequency we noted the appearance of higher order modes. These frequency boundaries represent the 160 degree phase deviation limits we imposed on our test fixture design for accuracy. 
Comparisons of the effectiveness of various cell configurations are made with respect to a standard (unmodified) cell in Figure 4. In a standard cell, the strongest transverse resonance occurs at about $820 \mathrm{MHz}$. After the cell was modified with a metal corner reflector and feedline ferrites, there was a significant drop in the resistance. In a subsequent experiment, a slight improvement over this was achieved by covering the metal corner reflector with a thin layer of RF absorber. Table 1 lists the maximum resistance and its frequency for each of these cases.

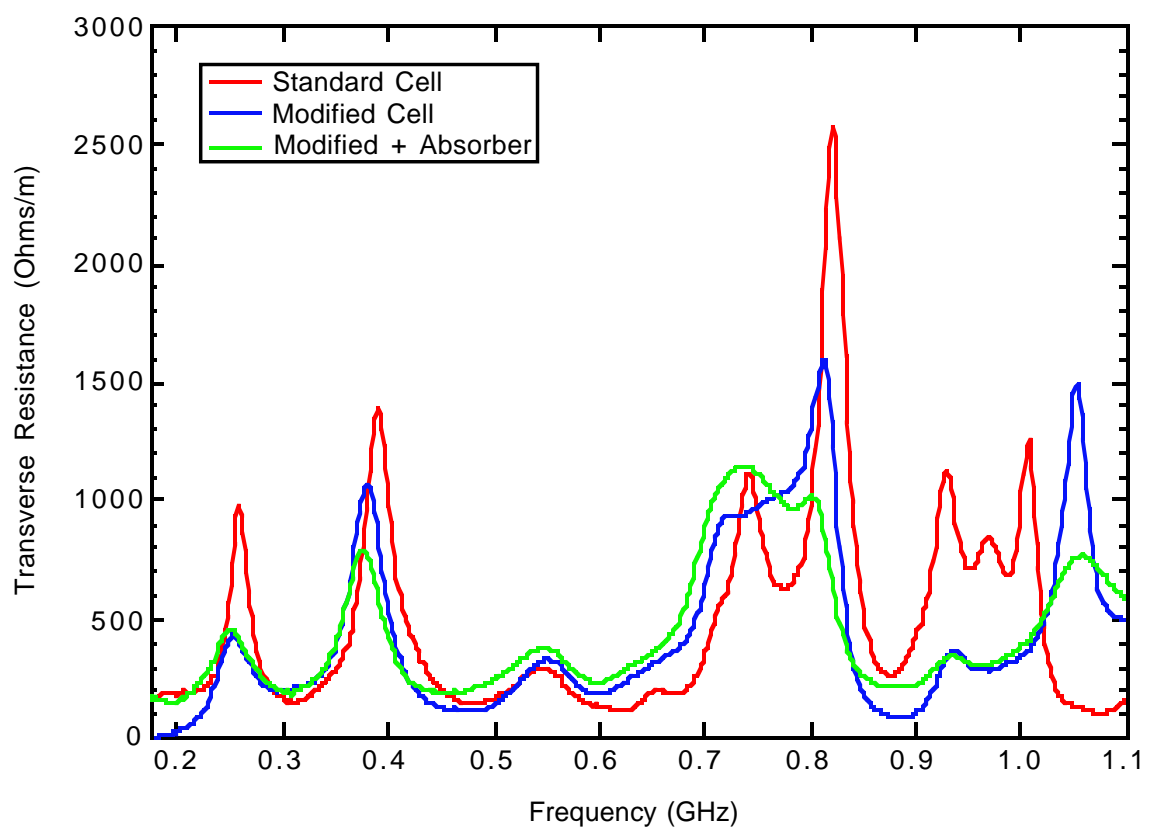

Figure 4. Standard vs. modified cell

Table 1. Resistance vs. Peak Frequency

\begin{tabular}{|c|c|c|}
\hline Case & $\begin{array}{c}\text { Max. Resistance } \\
(\Omega / \mathbf{m})\end{array}$ & $\begin{array}{c}\text { Peak Frequency } \\
(\mathbf{M H z})\end{array}$ \\
\hline Standard & 2570 & 821 \\
\hline Modified & 1600 & 813 \\
\hline Modified + Absorber & 1140 & 737 \\
\hline
\end{tabular}

\section{Embedded Ferrite Tests}

We also tested a large ferrite toroid embedded in the end plate of the accelerating gap. The type of ferrite that was tested is of high efficiency and low loss, which dispersed most of the energy towards the lower frequencies (Figure 5). A lossier ferrite would have been preferable but was not available in time for these tests. Consequently, the peak transverse resistance remained quite high, although shifted to a lower frequency. Also, the 'Q' of the resonance is lower than in the standard cell. Although a lossier ferrite might be expected to provide higher attenuation over the entire frequency band, these results represent an improvement in performance since beam break-up is also proportional to resonant frequency and the 'Q'. 


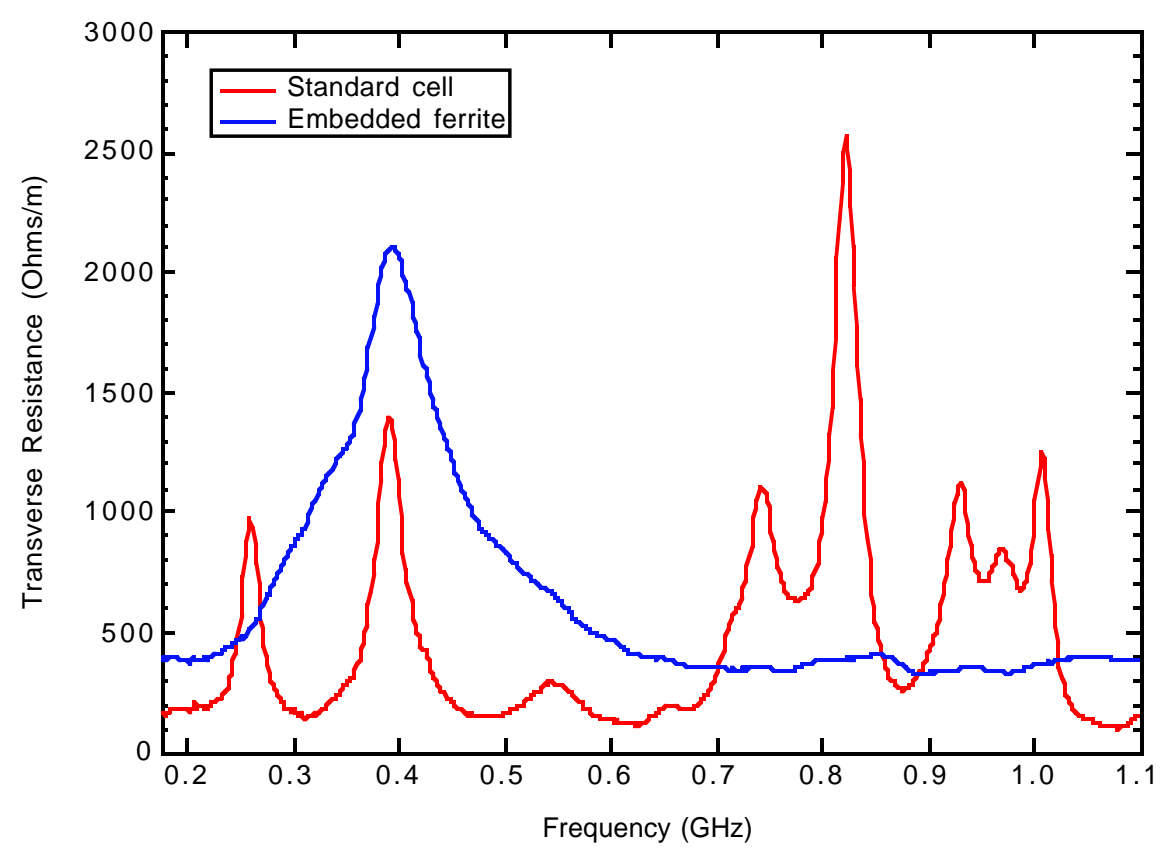

Figure 5. Standard cell vs. embedded ferrite

\section{Comparing Measured and Computed Results}

The measured and computed response [5] of the embedded ferrite compare favorably, as shown in Figure 6. A slight difference in peak frequency is most likely due to small differences in geometry. The difference in amplitude is due to differences in material electrical parameters and thickness. Computationally, the impedance of the cavities varied appreciably with Ferrite thickness and location of embedded Ferrite due to embedded inset to gap.

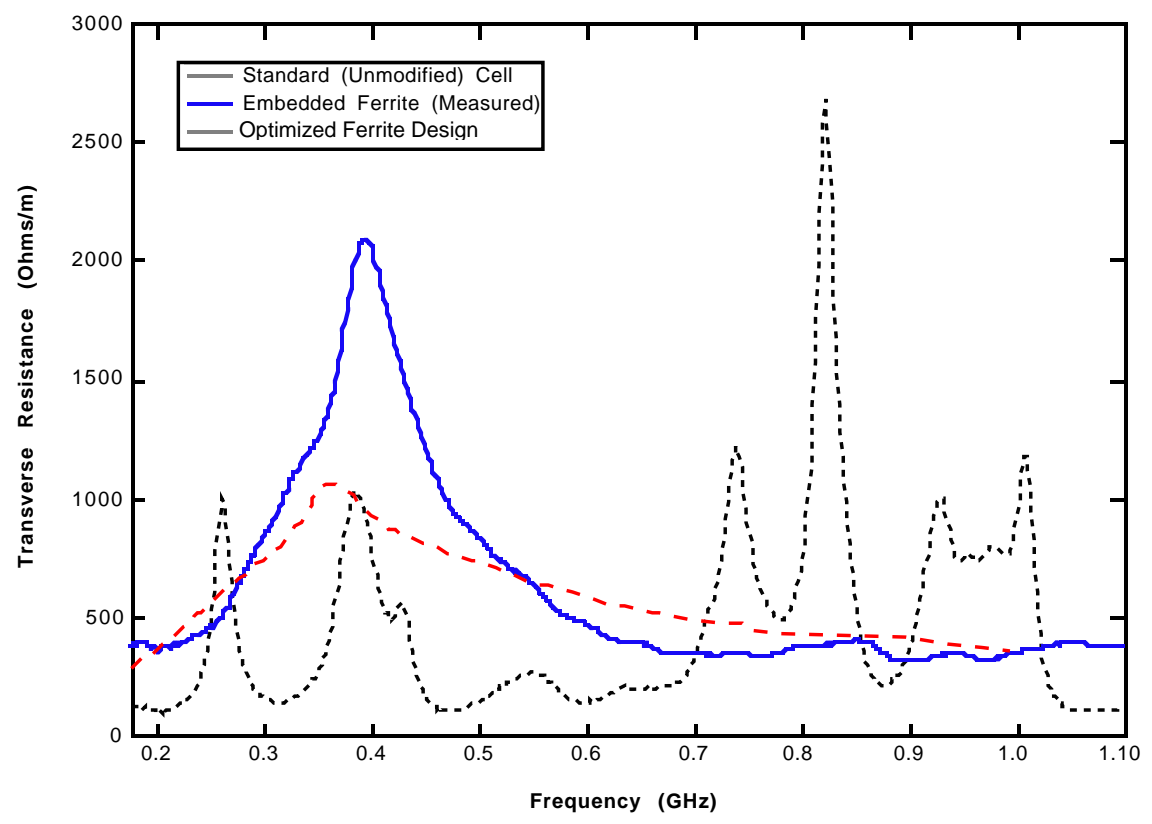

Figure 6. Comparison of experimental and computed values 


\section{RF Absorber Tests}

We also tested carbon-loaded RF absorbers of various grades and thicknesses. These are low-density, high-loss, flexible foams that conform to the inner wall of the vacuum housing. All of these absorbers reduce the impedance as shown in the Figure 7 family of plots. Their performance is somewhat dependent on attenuation and thickness, and although these are linear lossy materials some energy redistribution is still evident, possibly due to the combined effects of the absorber and the magnet ferrites. All of these measurements were done at atmospheric pressure, and possible use in the cavity would depend on how well these materials perform in a vacuum. Some types of low-outgassing silicon rubber absorbers may be suitable.

Measurements shown in Figure 7 were done with $6 \times 24$ inch sheets of absorber joined at the ends and wrapped around the inner cell wall. Since the vacuum port opening through which the absorber might be inserted into the cell is slightly over four inches in diameter, we compared the performance for six- and four-inch wide strips of the same grade and thickness. Results shown in Figure 8 are close enough that no significant advantage would be gained by using the wider strip.

\section{Conclusions \& Recommendations}

- The embedded ferrite provided the highest attenuation above 500 $\mathrm{MHz}$, however, the type of ferrite we tested was a "high-efficiency" ferrite with little loss, and most of the energy appears to have been redistributed to a lower frequency by dispersion. Even though the peak resistance remained quite high, these results represent an overall improvement in performance (e.g., 800 $\mathrm{MHz} \mathrm{BBU}$ mode) since beam break-up is also

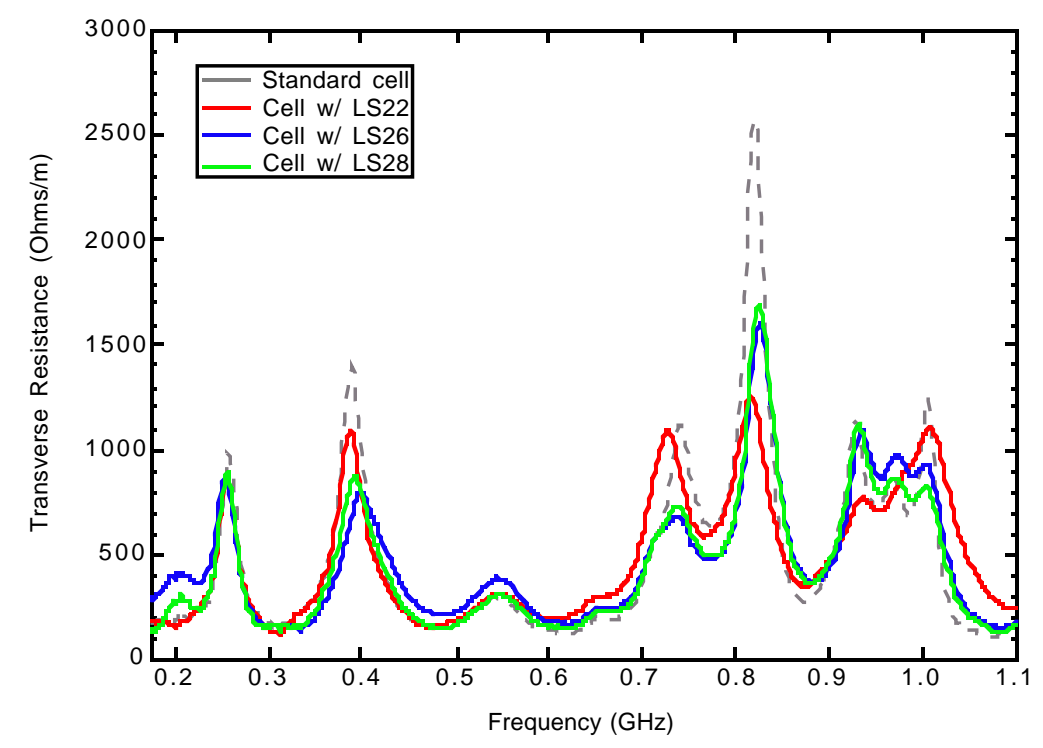

Figure 7. Standard cell vs. cell with absorbers

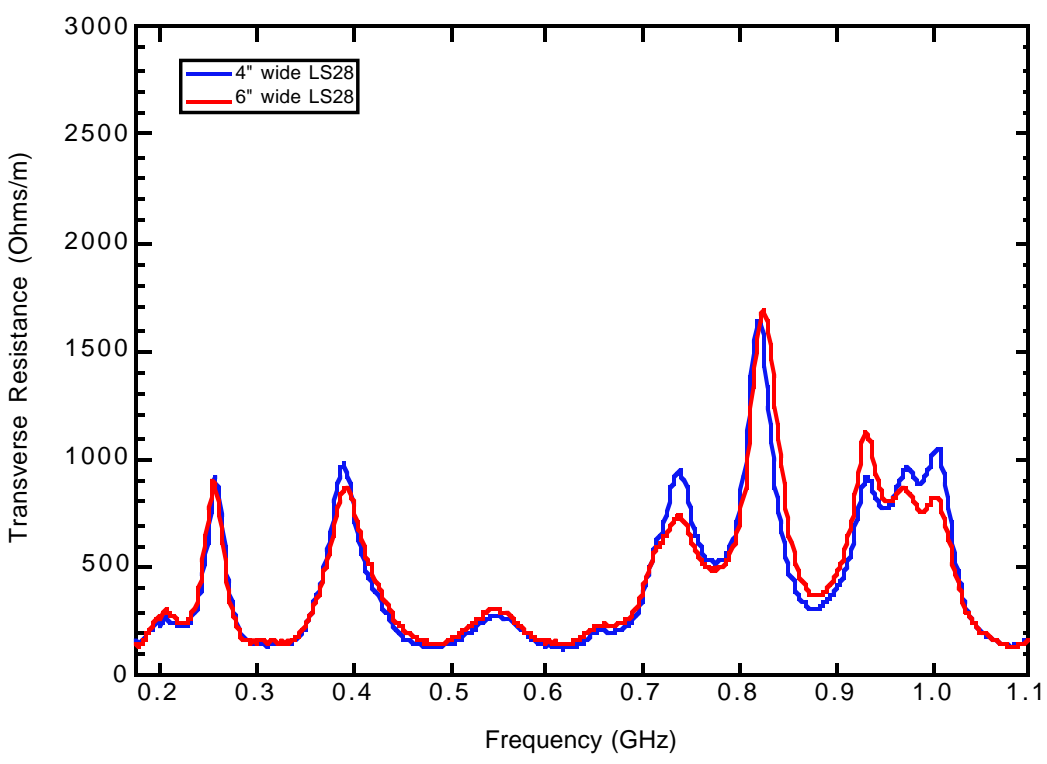

Figure 8. Comparison of performance vs. absorber width 
proportional to resonant frequency and 'Q', both of which were significantly reduced. Lossier types of ferrites would be expected to provide higher attenuation over the entire frequency band. Although this solution may be the best in terms of performance, this option will be difficult to implement due to the extensive cell modifications that would be required.

- Carbon loaded absorbers in the vacuum housing have also been shown to be effective. The peak resistance at $820 \mathrm{MHz}$ was reduced by as much as $58 \%$, down to $<1.1 \mathrm{~K} \Omega / \mathrm{m}$ when combined with a corner reflector and feedline ferrites (compared to $2.6 \mathrm{~K} \Omega / \mathrm{m}$ for the standard cell), and down to $1.3 \mathrm{~K} \Omega / \mathrm{m}$ without the reflector and ferrites. A flexible, lowoutgassing absorber could be inserted into the housing through the vacuum port with a minimum of down time and disassembly. There are several commercial absorbers of this type that may be suitable, or a custom design for the application may be required. More tests would be needed to demonstrate vacuum compatibility of these materials.

- Model and experiments are in close agreement. Better agreement would be achieved by closer matching of geometry and material parameters.

\section{Acknowledgments}

I would like to acknowledge the support of Ray Scarpetti, FXR upgrade project leader, Jim Dunlap and Greg Earley for their technical help with the measurements, Scott Nelson for permission to print results of his cavity model, Lorna Naugle and Lyn Ahboltin for document preparation.

\section{References}

1. R. Scarpetti, J.M. Zentler, J. Boyd, G. Early, R. Kihara, K. Griffin, "Upgrades to the LLNL Flash X-Ray Induction Linear Accelerator (FXR)," Lawrence Livermore National Laboratory, UCRL-JC-128385, presented at the "11th IEEE International Pulsed Power Conference," Baltimore, MD; July, 1997

2. M. Ong, C. Avalle, R. Richardson, J. Zentler, "LLNL Flash X-Ray Radiography Machine (FXR) Double-Pulse Upgrade Diagnostics," Lawrence Livermore National Laboratory, UCRL-JC-125879, June 26, 1997, http://www.llnl.gov/tid/lof/documents/pdf/231850.pdf

3. R. J. Briggs, D. L. Birx, G. J. Caporaso, V. K. Neil, and T. C. Genoni, "Theoretical and Experimental Investigation of the Interaction Impedances and Q Values of the Accelerating Cells in the Advanced Test Accelerator," Part. Accel. 18 41-62 (1985).

4. L.S. Walling, D.E. McMurry, D.V. Neuffer and H.A. Thiessen, "Transmission-Line Impedance Measurements For An Advanced Hadron Facility," Nuclear Instruments and Methods in Physics Research, A281, 1989.

5. S. D. Nelson, "EM Modeling of the FXR Accelerator Cavity," Lawrence Livermore National Laboratory, UCRL-MI-120539, 1993. 


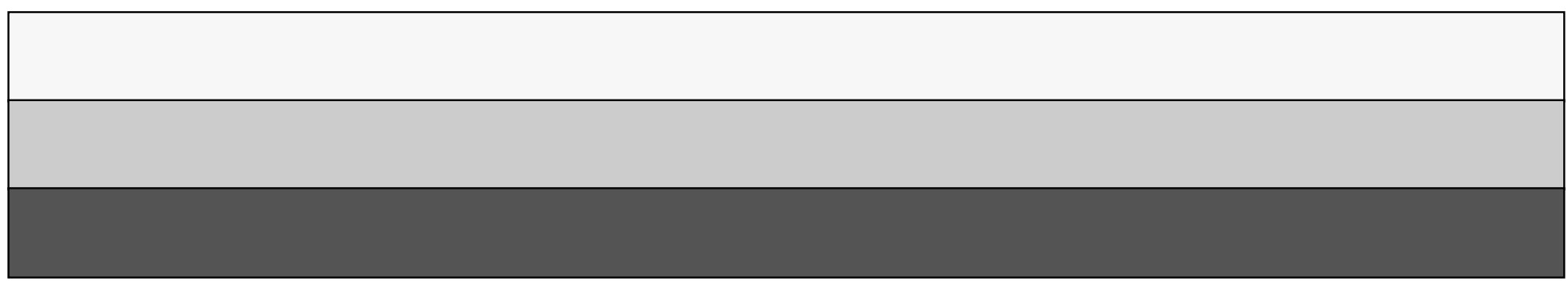

